\title{
As razões dos gestores - Entrevista com Maurício Holanda Maia
}

Neste número dedicado ao estudo de políticas para o ensino médio, nada mais importante do que ouvir um gestor público, alguém que, embora sob um conjunto de constrições, toma decisões sobre a formulação de políticas educacionais, dentre elas as que aqui estudamos.

Entrevistamos, neste número, alguém que há muito gostaríamos de entrevistar para Cadernos Cenpec. Tanto Joana Buarque como eu, que realizamos a entrevista, conhecemos Maurício Holanda Maia há muito - há quase (o que nos surpreende) duas décadas.

Joana, com Vanda Ribeiro, percorreu o Ceará e suas escolas, e ouviu especialistas em educação para realizar a sistematização do Paic (Programa de Alfabetização na Idade Certa), de cuja equipe central Maurício participou e do qual foi uma de suas principais lideranças. Eu já não me lembro exatamente como o conheci, no início da década de 2000. Talvez tenha sido numa das discussões promovidas pelo MEC (Ministério da Educação) ou pelo Inep (Instituto Nacional de Estudos e Pesquisas Educacionais Anísio Teixeira) sobre os primeiros resultados da experiência de Sobral, onde atuou como secretário de Educação. A reunião foi com um grupo de especialistas em alfabetização que se recusou a reconhecer os bons resultados dessa experiência e a buscar compreender os processos que conduziam 
a eles, dentre outras coisas, porque se avaliava a alfabetização por um teste de fluência em leitura - heresia maior ainda - num texto selecionado de acordo com determinada complexidade e num tempo cronometrado. Eu achei, ao contrário, que a experiência - mesmo desafiando alguns de meus pressupostos - tinha muito a ensinar. Fui execrado e excomungado. Mas, desde então, surgiu, entre mim e Maurício, um forte laço de cumplicidade e confiança. Acompanhei, a distância, a criação do Paic, com alguma apreensão em decorrência de seu documento inicial, publicado pela Assembleia Legislativa do Estado, criar desnecessárias oposições no campo da alfabetização.

Mas pude, também a distância, e em esporádicos encontros com Maurício e sua equipe, ir, com satisfação, me inteirando das conquistas do Paic. Depois, tendo deixado a UFMG (Universidade Federal de Minas Gerais) e o Ceale (Centro de Alfabetização, Leitura e Escrita), as próprias políticas do Ceará (juntamente com as do Acre) tornaram-se, ao iniciar meu trabalho no Cenpec, objeto de minha pesquisa (e da Joana). Primeiro, as relativas aos anos finais do ensino fundamental; depois, o próprio Paic e, por último, o ensino médio.

A essa altura, Maurício já havia se tornado, em dupla com Izolda Cela, secretário-adjunto da Educação do Estado e, depois, secretário da mesma pasta. A admiração que temos por ele - e que nunca foi um impedimento para a realização de nossas pesquisas, pois uma de suas características é a abertura para conversas francas e para o contraditório - só aumentou. Talvez por algumas razões, que o distinguem de outros gestores.

Maurício tem uma profunda identificação com a escola pública, porque dela é fruto, porque sabe que deve a ela o que é. Quando digo “o que é” não me refiro apenas a uma posição social, mas ao conjunto das disposições adquiridas na escola, dos esquemas que organizam nosso modo de pensar e agir. Sendo fruto dessa escola, tem um profundo compromisso com ela e uma profunda crença em seu poder de, por meio do conhecimento, modificar as trajetórias pessoais e sociais, desde que a escola seja de qualidade e os alunos também se esforcem em alguma medida. É importante ressaltar que a categoria “esforço" (e mérito, evidentemente) é ela mesma uma categoria escolar, e é sempre tensionada (como se verá na entrevista) por uma clara percepção das desigualdades de partida e da necessidade de busca de equidade.

Acredito que seja essa crença que o anima, aliada a um forte senso prático e a uma grande criatividade, a fazer o que é possível para dar o mesmo que teve - a mesma experiência que viveu - ao maior número de estudantes que 
puder. "O que é possível”, aqui, tem um sentido tanto de "esforço ilimitado" ou de "grande dedicação" como de "limitação". Apesar de todos os esforços, como Maurício mesmo diz numa entrevista para uma de nossas pesquisas, um gestor tem sua ação limitada por um conjunto de restrições políticas, orçamentárias, humanas. Referindo-se à implementação parcial de escolas de tempo integral, diz algo como: sim, causaremos um problema de equidade; a balança da justiça penderá para um lado, mas pelo menos alguns - que são muitos - poderão ter suas vidas mudadas pelo acesso a escolas de excelente qualidade.

Por último: Maurício e seu grupo sabem que seu "tempo é agora”, que cabe a eles a responsabilidade de responder agora às necessidades do presente, mas que essas respostas podem também contar com um legado do passado. Tendo trabalhado com Antenor Naspolini e Sofia Lerche Vieira, que o antecederam na Secretaria de Educação, Maurício certamente promoveu rupturas com o passado. Soube também, porém, apoiar-se no legado de seus antecessores, especialmente na tradição municipalista cearense que todos souberam tão bem explorar.

Maurício é doutor em Educação Brasileira - Política Educacional pela Universidade Federal do Ceará, onde também foi professor. Atualmente voltou a atuar como consultor legislativo da Câmara de Deputados na área de educação.

Antônio Augusto Gomes Batista 
CADERNOS CENPEC - PARA COMEÇAR, GOSTARÍAMOS DE FALAR SOBRE A ESPECIFICIDADE DE SER UM GESTOR NO CEARÁ. HÁ UMA ESPECIFICIDADE CEARENSE QUE INTERFIRA NA IMPLEMENTAÇÃO DA POLÍTICA PÚBLICA?

MAURÍCIO HOLANDA MAIA - Talvez... Se, como nordestino, me distancio e olho para os fatores estruturais da economia da minha região, diria que somos todos pobres. Temos uma economia desmonetarizada, focada no consumo, concentrada em torno de poucas cidades, as capitais. No interior, o estado e os governos municipais são os grandes empregadores e movimentadores de capital. Nessas condições econômicas tendem a se reproduzir as práticas clientelistas e patrimonialistas que dão feição à cultura política nordestina - e brasileira. Nisso também não somos diferentes. No entanto, algumas políticas sociais iniciadas no Ceará, como os agentes comunitários de saúde, na década de 1990 ou o Paic, nos anos recentes, foram capazes de melhorar significativamente a situação da saúde e da educação básica. Então, eu não sei se essa especificidade existe num nível realmente consistente ou se ainda são episódios isolados derivados de atitudes e medidas de gestão pública diferenciadas da parte de políticos como Tasso Jereissati, Ciro e Cid Gomes. De toda maneira, bons exemplos repercutem no imaginário dos cidadãos, na cultura organizacional das burocracias do estado e na formação de quadros para a gestão pública, imagino.

No que diz respeito, especificamente, às políticas educacionais, o Ceará se beneficia de um longo ciclo de cooperação estado-municípios baseada em critérios universais. Falo da superação (parcial, mas já efetiva) da cultura política que leva os governos estaduais a lidarem com os municípios unicamente em termos de prefeitos aliados e prefeitos inimigos. Trata-se, pois, de construir uma agenda capaz de relativizar a filiação partidária dos prefeitos de modo a garantir ampla articulação com os municípios em benefício da melhoria da oferta de educação pública. Não conheço bem os antecedentes, mas vi de perto essa atitude desde 1995. Acredito que esse cenário foi acumulando confiança, ou, melhor dizendo, capital social. O Naspolini foi um grande fiador dessa atitude nas suas gestões; continuou com a Sofia e depois com a Izolda ${ }^{1}$, no governo Cid. Acho que de 2007 para cá demos um enfoque explícito e uma ênfase ainda mais forte a esse compromisso, certamente em cima de um alicerce sólido, de experiências anteriores que permitiram talvez andar mais rápido. E também devido ao fato de o então governador Cid Gomes ter sido antes gestor de um município do interior do estado - Sobral. Aliás, Sobral também foi nossa escola de gestão - para a Izolda e para mim.

Antenor Naspolini, Sofia Lerche Vieira e Maria Izolda Cela de Arruda Coelho foram secretários de Educação do estado do Ceará. 
CAdernos CenPeC - Vamos falar sobre o Paic. AlÉm de ser EXTREMAMENTE POSITIVO EM RELAÇÃO À ALFABETIZAÇÃO DAS CRIANÇAS, UMA PESQUISA REALIZADA PELO CENPEC MOSTRA QUE O PROGRAMA CONTRIBUI MUITO PARA A GARANTIA DE EQUIDADE, TENDO BENEFICIADO ESPECIALMENTE OS MUNICÍPIOS MENORES E OS ALUNOS MAIS POBRES ${ }^{2}$. É RECONHECIDO POR VÁRIOS PESQUISADORES E INSTITUIÇÕES, INCLUSIVE O MEC, QUANDO FAZ o Pacto nacional pela Alfabetização na Idade Certa (Pnaic); mas, ao MESMO TEMPO, É MALVISTO PELO CAMPO UNIVERSITÁRIO. A QUE VOCÊ ATRIBUI ESSAS CRÍTICAS?

MAURÍCIO HOLANDA MAIA - Sinceramente, acho que há no Brasil um processo de ideologização da discussão nas faculdades de educação que está deixando a universidade cega para determinados aspectos da realidade. Não estou dizendo com isso que todos deviam elogiar o Paic, estou dizendo que seria bom se dispor pelo menos a conhecer mais para poder falar mal ou bem com consistência. Então, acho lamentável. Inicialmente, a crítica, explícita ou não, era: "Vocês estão treinando os meninos para saber soletrar, para saber dizer o bê-á-bá de uma forma mecanicista”. A única coisa a fazer era esperar o tempo passar para que provássemos que não era isso. Hoje está claro que o Paic tem ações de literatura e de formação de leitores. 0 resultado dos meninos em fluência cresce, os resultados nos testes padronizados crescem no $5^{\circ}$ e no $9^{\circ}$ ano. E as pessoas continuam a dizer que estamos treinando. Num debate numa universidade paulista me perguntaram como nós conseguíamos "treinar” os alunos para as provas. A minha resposta foi: "Olha, até onde eu sei, a seleção de vôlei é medalha de ouro porque treina pra caramba, mas infelizmente não temos capacidade gerencial para treinar centenas de milhares de crianças”. É uma resposta tosca, à altura da má vontade da pergunta. Sinceramente... se formos tratar as coisas nesses termos, eu poderia argumentar que as escolas particulares tidas como melhores do país fazem exatamente isso, treinar, e é nelas que a grande maioria dos professores das faculdades de educação que criticam o Paic matriculam seus filhos. A verdade é que a questão não fica bem colocada se o fazemos em termos de um antagonismo entre treinar e educar. A pergunta que me faço quando há crítica explícita de setores da universidade ao trabalho de Sobral e ao Paic é: será que quem critica se deu ao trabalho de verificar o que está sendo feito? Ou está criticando de ouvir

Entre 2007 e 2011 o Ceará mais que dobrou o percentual de alunos que atingiram 200 pontos ou mais na escala do Sistema Nacional de Avaliação da Educação Básica (Saeb), sendo que as crianças de menor poder aquisitivo apresentaram maior crescimento. Mais informações da pesquisa podem ser acessadas no Boletim Educação \& Equidade, n. 2, disponível em: 〈http://www.cenpec.org.br/boletim/boletim02/〉. 
falar, negando a experiência em bloco? Eu acho que seria muito benéfico discutir para valer mesmo. Mas não tenho essa sensação com as críticas que ouvi até agora.

CADERNOS CENPEC - E EM RELAÇÃO ÀS CRÍTICAS QUE AFIRMAM QUE HÁ REDUÇÃO CURRICULAR, COMO VOCÊ SE POSICIONA? HOUVE UMA OPÇÃO EM FOCALIZAR SABERES ELEMENTARES, AQUELES FUNDAMENTAIS PARA QUE OS ALUNOS DOS ANOS INICIAIS POSSAM PROSSEGUIR OS ESTUDOS?

MAURÍCIO HOLANDA MAIA - Análises antigas, com dados do Saeb de 1995, 1997, 1999 mostravam que, em média, os professores da escola pública cumpriam apenas metade do programa dos livros didáticos. Isso sim é que é redução curricular. E quando nas aulas de inglês nas escolas públicas não se consegue ir muito além do to be, não é redução curricular? Agora, se eu honestamente declarar que o que vou fazer é menos do que eu desejava, mas que vou fazer mesmo, aí já sou criticado por propor redução do currículo. Acho isso irracional, tolice. Não existe maior redução curricular do que não garantir que o menino se alfabetize. Essa é a maior redução curricular que pode existir e é a que está existindo ainda hoje no Brasil, que produz $30 \%$ de meninos sem as competências mínimas no final do $3^{\circ}$ ano, aos 8 anos de idade. $E$ isso vem sendo tratado quase com indiferença por importantes setores da academia. Nesse sentido, a resposta para a sua pergunta é sim, houve. Não se conserta de uma só vez o que está errado há décadas ou há séculos. Primeiro trata-se de parar de "fazer de conta" para fazer de verdade o melhor possível. E isso significa também um compromisso prático e ético entre um ideal e um ideário pedagógico que deve sempre iluminar o horizonte e uma leitura realista das condições de atuação e quais passos dar primeiro para sermos capazes de andar mais rápido no futuro. Nesse sentido, é importante dizer o que é imprescindível, quais as metas e como vamos medir os resultados. É razoável considerar que talvez as escolas terminem fazendo opções pragmáticas em torno do que vai cair na avaliação. Esse tipo de acomodação acontece, mas em vez de negar a avaliação, o remédio é que estejamos atentos a ela para ir corrigindo. Francamente, acho que, depois de consolidada a competência de alfabetizar até 7 anos, o currículo de 3ํㅜ 4ํㅡ e 5ํanos, que corresponde mais ou menos a 8, 9 e 10 anos de idade, melhorou justamente por poder partir de uma base muito melhor. 
CADERNOS CENPEC - VOCÊS FIZERAM AJUSTES NAS EXPECTATIVAS DE DESEMPENHO AO LONGO DA IMPLEMENTAÇÃO DO PAIC?

MAURÍCIO HOLANDA MAIA - Sim. Já em Sobral, nas primeiras avaliações de alfabetização, era considerado alfabetizado quem sabia ler palavras isoladas; depois, só quem conseguia ler um texto com fluência. Ler um texto fluentemente é uma condição para a inteligência funcionar. Se eu ler uma frase no tempo natural de fluência, leio o texto inteiro e consigo entendê-lo. Isso é a condição para depois pegar um pequeno texto sobre descobrimento do Brasil e entender. Essa experiência nos dá a chave para pensar em uma maneira de ter acúmulos gradativos de qualidade. No Paic, teve um ano em que decidimos aumentar o nível de dificuldade das questões: a proficiência caiu e depois voltou a crescer, mas já com um critério mais rigoroso. Tem que ter sempre em mente que o conjunto de estratégias para um ano pode precisar ser revisto no ano seguinte. 0 próprio funcionamento do programa causa respostas que vão mudar o cenário e pedir novas equações. Outra coisa também é que mudamos a forma de calcular o resultado: em vez de usar apenas a média dos alunos de uma escola, passamos a calcular os índices de uma forma que fazia as escolas se preocuparem com a equidade, ou seja, que todos os alunos aprendessem o suficiente. Então, procuramos garantir que se aprendesse a ler e escrever com fluência... Conseguimos, pois bem, vamos pensar na matemática. Quando avançarmos mais um pouco na aprendizagem da leitura e da matemática, chegará a hora de trazer o desafio da educação científica das crianças. A propósito, está chegando a hora de começar a pensar em outro tipo de medição, que meça mais do que português e matemática.

CADERNOS CENPEC - NOS ANOS 1980 E EM PARTE DOS 1990 VIVEMOS CERTO DESAPONTAMENTO COM AS POLÍTICAS CURRICULARES. O RACIOCÍNIO PREDOMINANTE ERA DE QUE SERIA MAIS EFICAZ USAR A AVALIAÇÃO COMO VETOR DE MUDANÇAS CURRICULARES, QUE ELA TRARIA MAIS IMPACTO NA ALTERAÇÃO DE PRÁTICAS PEDAGÓGICAS. É ESSE O SEU RACIOCÍNIO?

MAURÍCIO HOLANDA MAIA - Eu dou pouca importância a documentos curriculares. Mudança curricular, valendo de verdade, é mudança de conteúdo e de metodologia operada pelo professor junto aos seus alunos. Então, para ter mudança curricular efetiva, que de fato saia do papel, é preciso se perguntar duas coisas fundamentais. Primeira: em que condições os professores trabalham? Lembremos que o professor aprendeu a trabalhar, desenvolveu um saber prático da sua profissão e que mudar o jeito de 
trabalhar dá trabalho. Então, se mudança curricular significa que você vai dar mais trabalho para o professor, pergunte-se quais são as facilidades, os incentivos e os apoios que você vai oferecer para que ele responda ao seu apelo. É preciso sentido, motivação e facilidades concretas para que o esforço adicional para a mudança não vire uma fonte de frustração. A segunda coisa: é preciso acreditar na mudança. Até aqui os documentos curriculares foram produzidos por pequenos grupos de especialistas que, após consolidar uma consulta mais ou menos ampla numa proposta, vai "vender a ideia" para toda a massa dos outros professores que não tiveram a sorte de ter sido chamados para conversar. Por que esses outros professores iriam acreditar nessa mudança? E isso não é só em relação à cultura de professor, também à cultura dos pais. Quantos casos ouvimos de escolas particulares ou públicas que tentaram inovar em sua abordagem de construção do conhecimento e os pais reagiram com dúvida e desconfiança, porque aquela escola não ensinava mais do jeito que eles próprios aprenderam? É preciso analisar onde você está querendo provocar a mudança e qual o contexto, qual é o arranjo ecológico dali. É preciso refletir por que você vai trazer elementos novos para aquele ecossistema. Não estou falando que tem que sair perguntando a opinião de todo mundo sobre todas as coisas. Mas temos que conversar calma, longa e seriamente com quem tem muito a ver com a mudança proposta. Meios para isso existem de sobra. Tempo também haveria, se entendêssemos que essa é uma construção que só se faz com calma e nos déssemos o tempo necessário.

CADERNOS CENPEC - DE SEU PONTO DE VISTA, PARA QUE SERVE A AVALIAÇÃO SISTEMÁTICA DA REDE?

MAURÍCIO HOLANDA MAIA - Inicialmente, em Sobral, a avaliação era uma maneira de monitorar metas e dar transparência e responsabilidade. É importante divulgar os resultados dos nossos esforços em garantir aprendizagem para esses meninos. Para tanto, precisamos avaliar. Avaliação padronizada não é nenhum abuso autoritário, é uma medida relativa, uma medida com que todos podem ser medidos razoavelmente. Eu imagino que, seja aqui ou na Finlândia, se você disser que os professores vão ser avaliados em função de resultados A, B ou C, a prática desse profissional vai responder em alguma medida a esse sinal. Mas também acredito que essas avaliações serão tanto melhores quanto mais elas forem discutidas com os professores e qualificadas a partir das muitas ressalvas que o professor faz aos instrumentos de medida e das suas considerações a respeito do contexto dos alunos avaliados. 
CADERNOS CENPEC - VOCÊS FIZERAM ISSO, DISCUTIR AS AVALIAÇÕES COM OS PROFESSORES?

MAURÍCIO HOLANDA MAIA - Em parte. Em Sobral houve todo um processo de aperfeiçoamento dos critérios para premiação de escolas. Foi um aprendizado importante. Acho que no Paic já há maturidade para iniciar um processo que inclua aspectos técnicos e sociais da avaliação. Por exemplo, reunir professores do 5 ano de um município, mostrar os resultados dos alunos deles e propor que questionem, levantem questões relevantes, significativas, consistentes para esse resultado. No que ele não é bom? No que ele pode ser melhor? O que mais podemos avaliar? Outro exemplo era a discussão extremamente legítima sobre avaliação de desempenho que cheguei a enunciar em conversas com o sindicato, isso já no ensino médio. Eles diziam: "Ah, não é justo você comparar o trabalho que eu consigo fazer na minha escola, aqui na periferia de Fortaleza, com o trabalho que a minha colega consegue fazer naquela escola lá do centro". Então, como é que vamos comparar? Eu provocava: e comparar você com você mesma no ano anterior é justo? Pois então, vamos conversar sobre isso, vamos descobrir outras formas de medir. Já pensou que maravilhoso, daqui a dez anos as medidas de desempenho em escola estarem muito além da medida padronizada de português e matemática da escala do Saeb? Isso só vai acontecer se abrir esse diálogo com os professores, que são os que mais entendem dessa questão na ponta. Contudo, se o avaliador olha para o professor pensando que ele está sempre buscando uma justificativa para não oferecer um bom resultado, e o professor olha para o avaliador e diz: "Esses caras estão sempre buscando uma forma de dizer que eu não faço bem o meu trabalho"... Assim, não tem como sairmos para um patamar mais qualificado de discussão sobre avaliação de resultados. Ainda caminhamos muito pouco nessa direção.

CADERNOS CENPEC - ENXERGAMOS NO TRABALHO DE VOCÊS NO ESTADO UM ELEMENTO DE TEORIA DE MUDANÇA QUEÉ A MOBILIZAÇÃO RELACIONADAÀ CRIAÇÃO DE MOTIVAÇÃO PARA A MUdANÇA. TEMOS DOIS EXEMPLOS; UM É DESCOBRIR UM MOTE QUE CRIE A PRÓPRIA MOBILIZAÇÃO, ALGO QUE UNA NÃO SÓ A COMUNIDADE ESCOLAR, MAS O CONJUNTO DA SOCIEDADE EM TORNO DE UMA CAUSA. NO CASO DO PAIC, QUe todos os ALUNOS SE ALFABETIZEM NA IDADE CERTA, QUE NÃO HAJA CRIANÇAS NÃO ALFABETIZADAS. NO CASO DO ENSINO MÉDIO, A CAMPANHA PARA QUE TODOS OS ESTUDANTES FAÇAM O ENEM (EXAME NACIONAL DO ENSINO MÉdio). O OUtro É o PrÊmio Escola Nota 10³. Certamente os ReCursos 
QUE A ESCOLA RECEBE PESAM, MAS A CERIMÔNIA DE PREMIAÇÃO É UMA FESTA, UMA CELEBRAÇÃO DAS ESCOLAS. A NATUREZA SIMBÓLICA DELA PARECE PESAR MAIS DO QUE A QUESTÃO DO GANHO FINANCEIRO. VOCÊ PODERIA COMENTAR ESSAS QUESTÕES?

MAURÍCIO HOLANDA MAIA - Eu acho isso importante, sim. Mas, antes, uma ressalva. Quando você diz "teoria de mudança” dá a impressão de que alguém tinha pensado nisso e planejado tudo com antecedência, mas não é assim. Os diversos temas, estratégias e formas de abordagem se organizaram em torno de uma meta, de uma consideração pelas práticas existentes e de princípios e valores que questionavam o status quo. A emergência de cada uma das soluções é muito situacional e, por vezes, circunstancial. Mas, sem dúvida, se pensarmos a posteriori sobre o que podemos aprender com a experiência vivida, faz todo o sentido dizer que uma teoria de mudança precisa pensar em como comunica e como mobiliza. A primeira coisa é que um mote precisa traduzir uma meta. E essa meta precisa ser clara. Ela pode e deve ser formulada mobilizando um sentimento de nobreza, de generosidade das pessoas, de compromisso social. Mas ela também deve ser mensurável e expressa em resultados facilmente compreensíveis. Precisa ainda de acompanhamento, inclusive de medidas intermediárias, porque não faz sentido esperar o fim do ano para medir e o começo do ano seguinte para descobrir o que não conseguiu. Finalmente tem essa dimensão da celebração, do prestígio, que é bom. No caso da participação massiva dos alunos do ensino médio no Enem, fico ainda mais impressionado, porque creio que identificamos o processo que é capaz de unir alunos, professores, gestores escolares, técnicos e dirigentes da Secretaria de Educação, além de pais, ex-alunos e autoridades municipais em torno de um objetivo síntese: fazer o Enem e conseguir entrar na universidade pelo Sisu (Sistema de Seleção Unificada) ou Prouni (Programa Universidade para Todos). Este ano, em plena greve e com escolas ocupadas, a comunidade escolar garantiu inscrição massiva no Enem. Isso diz muito, a meu ver.

com bons resultados na alfabetização e na aprendizagem da leitura e escrita de seus alunos. As escolas vencedoras prestam assessoria para escolas com baixos resultados. Ambos os conjuntos de escolas recebem recursos financeiros para implementação de projetos educativos e distribuição entre seus profissionais. 
CADERNOS CENPEC - A SEgUINTE IDEIA ESTÁ PRESENTE NO PAIC: "TODA CRIANÇA PODE APRENDER, INDEPENDENTEMENTE DO NÍVEL SOCIAL”. HÁ UMA DEFESA DE QUE NÃO HÁ A DESCULPA DE NÍVEL SOCIOECONÔMICO. HÁ TAMBÉM, PORÉM, POR PARTE DOS GESTORES PÚBLICOS, UMA AVERSÃO AO DISCURSO SOCIOLÓGICO, AO PROFESSOR QUE TRAZ A DIFICULDADE DE TRABALHAR EM UMA REGIÃO DE ALTA VULNERABILIDAde, POR EXEMPLO. Ao MESMO TEMPO QUE hÁ ESSE EFEITO DE CRIAÇÃO DA CRENÇA DE QUE “TODA CRIANÇA PODE APRENDER”, HÁ CONDIÇÕES MUITO DESIGUAIS. COMO VOCÊS LIDAM COM ISSO?

MAURÍCIO HOLANDA MAIA - O argumento sociológico de que determinadas condições socioeconômicas causam maiores dificuldades na aprendizagem de um determinado grupo de crianças é real. 0 problema é que durante décadas isso vem sendo utilizado no Brasil para justificar que a escola pública seja péssima e que os pobres não aprendam. Esse argumento extrapolou tanto que para que ele volte para o devido lugar precisamos ter uma recusa enfática dele. Não é razoável abstrair que todas as crianças submetidas a uma situação de extrema precariedade vão poder aprender de maneira igual aos outros sem apoios maiores, mas é perverso deixar que esse raciocínio naturalize um estado de coisas em que a escola pública tem sido demissionária da sua responsabilidade, da sua razão de existir.

CADERNOS CENPEC - ESSE É O CASO DAS DIFICULDADES QUE VOCÊS TÊM ENCONTRAdO EM FoRTALEZA PARA MELHORAR OS NÍVEIS DE QUALIDADE E EQUIDADE? SERÁ QUE NÃO HÁ RELAÇÃo DOS RESULTADOS COM OS EFEITOS DE UMA METRÓPOLE?

MAURÍCIO HOLANDA MAIA - Acho que o ambiente das periferias paupérrimas das grandes metrópoles tem um peso imenso nisso. Mas não é só renda. Qual é a forma de relações parentais que predomina nesse ambiente? Como é o cuidado de pai e de mãe? São muitas questões que as políticas precisam começar a incorporar. 
CADERNOS CENPEC - OS DADOS MOSTRAM QUE A EVOLUÇÃO DO IDEB (ÍNDICE de Desenvolvimento da EducaÇÃo BÁsica) no EnSIno fundamental II do Ceará É bem maior que a dos outros estados do Nordeste. Em 2015 CHEGOU A 4,5, ULTRAPASSANDO A MÉDIA NORDESTINA, DE 3,7, E A BRASILEIRA, DE 4,2 (O ÍNDICE dos demaIS ESTAdos VARIA DE 3,1 A 3,9). AO QUe VOCÊ ATRIBUI ESSA MELHORA?

MAURÍCIO HOLANDA MAIA - A tentação imediata é dizer que isso é resultado direto do Paic, que a melhoria da alfabetização já produziu uma nova geração, mais bem preparada, que está chegando ao 90 ano. Mas creio que não é tão simples assim. Há muitos fatores. Bom, a tese do Paic é, em suma, de que crianças alfabetizadas na idade certa estarão mais bem preparadas para aprendizagens posteriores. $E$ isso é verdade, mas não é suficiente. 0 foco, a atenção e os esforços da escola e do professor têm que se repetir a cada ano para cada uma das séries. E nesse quesito acho que o Paic já lançou bases sólidas até o 50 ano, mas não me parece suficiente para explicar o resultado do 9o. Outra hipótese é que teríamos nas redes municipais do estado um efeito de melhoria gerencial, que o senso de responsabilidade da escola com o resultado dos meninos transbordou do $5^{\circ}$ ano para o fundamental II. Acho que essa melhora vem da conjunção de muitos fatores: a geração que chega melhor ao $6^{0}$ ano, a cultura organizacional e de gestão pedagógica que transbordou e, mais recentemente, a ampliação das ações do Paic para essa etapa. E você vê que o Brasil também vem crescendo. Acho que tem uma coisa da onda nacional também.

CADERNOS CENPEC - HÁ POLÍTICAS MUNICIPAIS PARA O ENSINO FUNDAMENTAL II?

MAURÍCIO HOLANDA MAIA - Não tenho informações atuais e detalhadas. Tem Sobral, que há bastante tempo vem avaliando e premiando. A metodologia que eles tinham desenvolvido para alfabetização até $05^{\circ}$ ano já se estendeu do $6^{\circ}$ ao $9^{\circ}$ ano. Tem um município perto de Fortaleza - Eusébio -, do qual ouvi falar, e que já transformou toda a sua rede em tempo integral. Muitos, inclusive Fortaleza, estão ampliando sua oferta de tempo integral nessa etapa. Deve haver muitas outras iniciativas das quais não estou a par. Há muita criatividade e competência nas equipes municipais. No momento estou olhando para o 60 ao 9o, a segunda etapa do fundamental, de outro ponto de vista, que, no entanto é complementar e convergente. Venho colaborando de um programa de governo, o Ceará Pacífico, que está olhando para todas as dimensões do fenômeno violência e suas consequências. Isso vai desde 
a redução de homicídios, passando por educação prisional, segurança comunitária e sistema de medidas socioeducativas até cultura de violência contra a mulher, abandono escolar e bullying. Estamos buscando caminhos para a redução das ocorrências e atenuação da cultura de violência, procurando nos apropriar de conceitos e fazer experimentos com segurança cidadã, práticas de mediação e justiça restaurativa, integração e intersetorialidade dos serviços públicos, fortalecimento comunitário. 0 que percebo é que tudo isso tem muito a ver com escolas boas, com capacidade de conversar com a juventude e, de forma mais específica, com um olhar focado no ensino fundamental II, pois as turbulências na história de vida da maioria dos jovens em conflito com a lei se prenunciam nas turbulências que ocorrem entre $12 \mathrm{e}$ 15 anos na trajetória escolar deles.

\section{CADERNOS CENPEC - O ENSINO INTEGRAL SERIA A SOLUÇÃO NESSE CASO?}

MAURÍCIO HOLANDA MAIA - Para mim é a etapa prioritária para tempo integral. $06^{\circ}$ ao $9^{\circ}$ é a hora em que os meninos questionam as regras familiares e escolares, e às vezes rompem com a autoridade dos adultos (pais, professores) em benefício de seus pares. Se você implanta o integral com os alunos aos 11, 12 anos num processo pedagógico capaz de ressignificar a experiência de estar na escola, valorizando as relações com os colegas, com a escola e com o saber, isso é muito virtuoso e poderoso.

CADERNOS CENPEC - QUAL TEM SIDO A ATUAÇÃO DO GOVERNO DO ESTADO DO CEARÁ NA EDUCAÇÃO INFANTIL?

MAURÍCIO HOLANDA MAIA - O Paic sempre teve um eixo de educação infantil, mas focado na pré-escola. Fizemos uma diretriz curricular e formamos formadores municipais. O Ceará já atende 90\% das crianças de 4 e 5 anos. O que mobiliza minha atenção nesse tema é o que poderíamos e deveríamos fazer pelas crianças de 0 a 3 anos, que são apenas $25 \%$ atendidas em creche. Acho que para suprir essa falta de atenção com os mais pequenos não deveríamos pensar exclusivamente em creche. Mesmo que tivéssemos todo o dinheiro do mundo para todos os meninos de 0 a 3 anos estarem em creches, ainda assim deveria haver um programa de fortalecimento da capacidade paterna em estimular o desenvolvimento dos seus filhos. $E$ se não temos toda a grana que a educação (inclusive creche) precisa e merece, não podemos ficar parados. Nesse caso, faz mais sentido ainda ter um tipo de serviço anterior e complementar, focado no desenvolvimento da capacidade 
de pais (e demais membros da família que interagem cotidianamente com a criança) estimularem o desenvolvimento integral dos pequenos. Temos que lembrar ainda que há localidades pequenas e isoladas, onde não é razoável construir creche. Penso em um programa baseado em visitas domiciliares para monitoramento do desenvolvimento da criança de 0 a 3 anos. Dizer aos pais que é importante botar no colo e conversar, que perguntas de criança não devem ser respondidas com um "cala a boca, menino" e que essas coisas fazem muita diferença.

CADERNOS CENPEC - QUAL É A SUA POSIÇÃO SOBRE A AVALIAÇÃO NA EDUCAÇÃO INFANTIL?

MAURÍCIO HOLANDA MAIA - Penso que é preciso ter cuidado. Não vejo necessidade de que avaliações do tipo que hoje fazemos no fundamental e médio cheguem à educação infantil. Faz tempo, ainda em Sobral, que cheguei a perceber um risco de antecipação para a pré-escola da avaliação para alfabetização. Acho que é preciso ter muito cuidado com isso, colocar as coisas no lugar e tempo certos. Acho que quando se avalia alfabetização é feito um recorte de uma competência muito específica e muito fundamental da história escolar de alguém. Então, é preciso ter cuidado para não passar da medida trazendo elementos dessa racionalidade para crianças de 4 e 5 anos para a pré-escola. A primeira infância é quando, mais do que nunca, se aprende brincando. Avaliações no sentido de aferir o trabalho da escola, aferir o trabalho do professor podem trazer riscos de reduzir o significado do que é o processo educativo daquele momento. Do mesmo jeito que é importante saber que quando você está avaliando a alfabetização não está avaliando toda a aprendizagem e a inteligência dos meninos: você apenas está avaliando o êxito da escola em garantir uma competência que é fundamental para a aprendizagem dali por diante. A aprendizagem mesmo é muito mais do que aquilo. 
CADERNOS CENPEC - FALEMOS DO ENSINO MÉdIO. DAS QUATRO REDES ESTAdUAIS dE ENSINO MÉdIO QUE ESTUdAMOS NA PESQUISA “PolítICAS PARA O ENSINO MÉDIO: O CASO DE QUATRO ESTADOS", A CEARENSE É A QUE APRESENTA O MAIOR EFEITO NA POPULAÇÃO DE ALUNOS DE PERÍODO INTEGRAL, OU SEJA, QUE TEM TIDO MAIOR RESULTADO DE DESEMPENHO NOS ALUNOS, APESAR DE O NÍVEL SOCIOECONÔMICO DOS ESTUDANTES SER O MAIS BAIXO ENTRE OS DEMAIS ${ }^{4}$. A QUE VOCÊ ATRIBUI ISSO?

MAURÍCIO HOLANDA MAIA - Acredito que se aprende melhor os conteúdos do ensino médio quando estão vinculados à ideia de um desempenho concreto na sociedade como profissão, mesmo que o aluno não vá segui-la. No fundo, é o que o pessoal da sociologia marxista da educação e do trabalho defende, apesar de criticar essas escolas. Eles dizem que o trabalho é o princípio educativo em Marx. É no trabalho que você se realiza, que o homem constrói conhecimento. Mas criticam a educação profissional na escola brasileira porque seria alienada e alienante, pois estaríamos apenas adestrando trabalhadores. Há coisas válidas em suas análises, mas não vejo assim. Se nem em épocas ditatoriais a escola consegue adestrar trabalhadores, quiçá numa sociedade em que há liberdade de expressão. Pedagogicamente, aprender biologia pensando que eu vou ser enfermeiro é muito mais significativo do que aprender biologia para aprender o nome de algo que talvez caia no Enem. 0 fato de o Ceará ter optado por um modelo de escola de tempo integral profissional nunca me incomodou, mas acho que não devia ser uma oferta exclusiva. Tem aluno que quer apostar no propedêutico e estudar 12 horas por dia para ser aprovado em medicina. Qual o problema? Então, por que nessa escola não pode ter uma turma propedêutica? Mas uma coisa boa que conseguimos implantar nessas escolas é a ideia de protagonismo, de responsabilidade dos estudantes por si mesmos. 0 jeito que elas [as escolas] são não é exatamente o que eu queria, mas isso é que é aprender a ser gestor público, aprender a implantar as ideias dos outros (risos), e se sentir gratificado em contribuir com algo que não é o seu projeto, mas que tem um apurado positivo.

Os resultados podem ser vistos no artigo "Políticas para o ensino médio e desigualdade escolar: os casos do Ceará, Goiás, Pernambuco e São Paulo”, publicado neste número da Cadernos Cenpec. 
CADERNOS CENPEC - ENTRE 2007 E 2014, A MATRÍCULA NO ENSINO MÉdIO ESTADUAL NOTURNO DIMINUIU 53\% NO CEARÁ 5 . POR QUE HOUVE ESSA REDUÇÃO?

MAURÍCIO HOLANDA MAIA - Eu tenho duas hipóteses. Uma, a mais relevante, com sinal positivo e outra com sinal negativo. Ampliamos muito o número de salas de aula e de prédios escolares nos oito anos de vacas gordas construímos mais de cem prédios. Vamos fazer uma média: se você constrói cem prédios escolares com oito salas cada um, são 800 novas salas. Isso é um forte componente estrutural para poder reduzir o ensino noturno. É claro que a conjunção de demografia e melhoria do fluxo escolar vai fazendo com que mais meninos terminem na idade certa. $E$ se isso coincide felizmente com o momento em que se constroem mais salas de aula, é possível que uma parte disso seja um sinal muito positivo de melhoria da qualidade. $A$ segunda hipótese, residual, mas com sinal negativo, é que as escolas estejam encaminhando a clientela noturna para o EJA (Educação de Jovens e Adultos) sem o compromisso real com sua permanência e aprendizagem. As formalidades da cultura escolar no ensino regular já são um convite à deserção dos meninos trabalhadores. Aquelas regras que, em princípio, têm razão de ser, mas terminam por ser perversas, como, por exemplo, quem chegar 15 minutos atrasado não entra. É frustrante, porque o aluno simplesmente não consegue chegar em ponto depois de oito horas de trabalho.

Outra coisa é a reprovação. Fizemos uma experiência que se mostrou muito interessante que, por sinal, copiamos do Paraná. Em escolas que tinham muitas turmas noturnas, concentrávamos, por exemplo, química no primeiro semestre e física no segundo, de modo que havia sempre pelo menos a possibilidade de concluir uma parte das disciplinas. Por quê? Porque dessa maneira você respeita a situação de alunos que têm empregos sazonais. Por exemplo, vendas de Natal. Não tem trabalho o ano todo, mas na época de Natal tem trabalho no comércio. São dois meses somente, mas são dois meses de salário. Então, no regime anual ele reprova no finalzinho em todas as disciplinas, no semestral ele conclui metade. Este é um exemplo de como organizar as coisas de outra maneira, mas a verdade é que ainda estamos devendo uma proposta decente de ensino noturno, que não seja um aligeiramento, mas que também não seja simplesmente manter a rigidez do número de horas - ou do faz de conta do número de horas do noturno em relação ao diurno dentro de um ano. Não é razoável esperar que os meninos

Mais informações no artigo "Políticas para o ensino médio e desigualdade escolar: os casos do Ceará, Goiás, Pernambuco e São Paulo", publicado neste número da Cadernos Cenpec. 
tenham quatro, cinco horas à noite e façam tudo em três anos se eles podem fazer com menos tempo a cada dia em quatro ou em cinco anos. Acho que realmente devemos isso aos muitos brasileiros que gostariam de voltar à escola no noturno.

CADERNOS CENPEC - QUAL É O CRITÉRIO PARA INGRESSO NA ESCOLA PROFISSIONAL? POR QUE FOI CRIADA UMA SELEÇÃO?

MAURÍCIO HOLANDA MAIA - São as notas constantes do histórico do fundamental II. Se fizéssemos provas, agravaríamos muito a seletividade; repetiríamos o que acontece nos Institutos Federais de Educação: há seis candidatos para uma vaga e será um menino de uma escola particular boa que vai pegar a vaga. Se você usa algo aleatório como sorteio ou ordem de chegada, seria talvez justo, mas não é virtuoso, não induz a uma busca de virtude. Então pegamos as notas do histórico do $6^{\circ}$ ao $9^{\circ}$ ano. Por quê? Bom, não importa se minha escola é mais ou menos boa, mas se as minhas notas foram boas, ou seja, dentro do que me ofereceram eu me esforcei e fiz o melhor possível, posso ser selecionado. É objetivo, mais meritório do que o sorteio e menos excludente do que a prova de conhecimentos. Além disso, dá um sinal muito interessante para os meninos do 60 ao 90: "Tem a perspectiva de estudar na escola profissional. Então começa a levar a sério os estudos desde já”. Acho que isso pode produzir comportamentos mais virtuosos para um grupo muito grande, inclusive para meninos que, mesmo que não entrem, terão aprendido mais do que se não houvesse esse sinal.

CADERNOS CENPEC - O QUE VOCÊ TEM A DIZER SOBRE A MEDIDA PROVISÓRIA DO ENSINO MÉDIO?

MAURÍCIO HOLANDA MAIA - Desde já, tem o problema de ser uma medida provisória, o que tira toda a legitimidade da alegação de que o tema foi amplamente debatido. Não foi amplamente debatido e, mais importante, não acho que foi debatido da forma mais adequada. Isso tem a ver, entre outras coisas, com o que eu falava sobre pressa na proposição de mudanças curriculares. E tem a ver também com a forma muito peculiar com que nós, no Brasil, nos relacionamos com a ideia de lei e da capacidade de mudar a realidade por meio de dispositivos legais. No Brasil, as pessoas pensam que as leis vão modificar a realidade, e elas não vão. Aqui, leis, ou pelo menos leis que acenam com a promessa de melhoras na área social, no máximo conseguem garantir que o assunto continuará na agenda política, que os grupos de advocacy do 
tema continuarão tendo motivos para defender sua bandeira. Ou seja, de que alguém vai continuar tendo mote e motivo para reclamar do Estado, porque a lei tal diz que é dever do Estado fazer isto e aquilo e ele ainda não fez. Não estou desqualificando as razões nem a racionalidade dos que operam com essas regras. $O$ fato é que ainda não temos regras melhores para o nosso jogo democrático, mas desse jeito tem muita ilusão e frustração. Mas, voltando à MP, o traço mais evidente da medida foi a retirada de obrigatoriedades, 0 que em si não é ruim. Seria mesmo ótimo se fosse expressão de confiança na capacidade de autorregulação dos sistemas educacionais, mas não é. Outra coisa é que se, infelizmente, precisa haver obrigatoriedade em lei para que se ensinem filosofia, sociologia e artes, a retirada da obrigatoriedade realmente é lida como risco de extinção dessas disciplinas. Um tratamento adequado de sua pergunta demandaria muitas páginas extras, mas para sintetizar, diria que perdemos mais uma oportunidade de tratar do necessário ajuste curricular do ensino médio de forma inteligente e democrática. Os acordos de que precisamos poderiam estar sendo construídos não como lei, mas como debate, como estudo, como experiências para serem feitas e se aprender com elas. E tudo isso podia estar sendo feito com uma discussão muito democrática com um cidadão que tem especial interesse por isso, que se chama aluno de ensino médio. Poderia ter feito um grande processo de reflexão no Brasil inteiro, utilizando ferramentas de informática, consultas, participação em fóruns virtuais, chamando os meninos para a conversa.

Você não consegue mudar currículo no Brasil sem uma base social. Nesse caso, a base social não pode ser os professores, tinha de ser os alunos. São alunos que já sabem o que querem, que já sabem falar. A voz do aluno aqui é imprescindivel, porque o professor sozinho não resolve essa equação. Pense como um professor, ele dirá: é verdade que o currículo está inflado, preciso de mais tempo para as minhas aulas, logo devíamos reduzir em outras disciplinas que não a minha. Mas a pressa e a pressão por respostas que deem a impressão de que o assunto foi resolvido é muito forte, embora cause muito alvoroço, seguido de imobilidade. Sou a favor de flexibilização e diversificação para que alunos escolham seus itinerários, mas tudo isso poderia ser uma construção real e discutida, em vez de mais uma luta em que vence quem consegue ser mais autoritário.

\section{CADERNOS CENPEC - QUAL É A SUA AVALIAÇÃO DAS PROVAS DO ENEM?}

MAURÍCIO HOLANDA MAIA - Já fizemos menção ao Enem quando falamos da mobilização que acontece no Ceará em torno das inscrições, da preparação 
e do comparecimento às provas. É muito forte ver que todos os atores de uma rede educacional são capazes de superar ou suspender suas diferenças em torno de um objetivo unificador ${ }^{6}$. 0 fato é que um conjunto de medidas de favorecimento do acesso ao ensino superior foi capaz de mudar a crença de centenas de milhares de alunos da escola pública brasileira. O Enem/ Sisu não seria o que é se dissociado da ampliação de vagas na rede federal, da ampliação do acesso a vagas públicas em instituições particulares via Prouni e, sobretudo, da lei de cotas sociais. Mas o Enem é em si mesmo uma grande conquista para a educação brasileira. Primeiro ele é, do ponto de vista metodológico, como instrumento de aferição de conhecimento, uma prova, no mínimo igual, mas acho que muito superior a qualquer prova de vestibular que uma universidade individual possa vir a fazer. Segundo, é uma prova que os estudantes pobres dos mais longínquos rincões do país podem fazer se inscrevendo pela internet e comparecendo a um local de prova situado a distância razoável em relação a sua moradia. Isso é altamente inclusivo. Quem deixa de lanchar para pagar a passagem de ônibus ou deixou de se inscrever em exames vestibulares porque não tinha a grana da viagem e da taxa de inscrição sabe avaliar o que estou dizendo. Finalmente, ao fornecer uma nota que é base para a competição por uma das mais de 100 mil vagas federais e estaduais disponibilizadas no Sisu, além do Prouni, o Enem aperfeiçoa o caráter meritocrático e competitivo de um sistema que já deixava de fora largos contingentes excluídos por falta de condições econômicas.

No momento, estou muito temeroso com alguns sinais vindos do Ministério da Educação e de intelectuais próximos ao stablishment. Tenho ouvido críticas ao Enem, críticas, ao que parece, bem-intencionadas, por exemplo, de que a participação dos alunos pobres no Enem ainda é limitada. Ora, então trabalhemos propostas para ampliá-la. Nós, do Ceará, temos muitas ideias para oferecer. Outro argumento que ouvi é de que alunos de regiões ricas estariam tomando vagas de alunos das próprias regiões pobres. Até onde sei, isso não bate com os dados das instituições federais localizadas no Ceará. Mas se fosse este o caso, enfrentemos a realidade. Não queremos esse tipo paternalista de reserva de mercado de vagas das instituições localizadas em nosso estado para alunos medianos de nosso estado. Que venham os manos de outros lugares do Brasil. São bem-vindos. Talvez me engane, mas penso que meus argumentos aqui representam bem o espírito de sonho e de crescente

6 Da campanha anual para que todos os estudantes façam o Enem, participam desde sindicatos docentes a associações de funcionários da Secretaria de Educação, que se organizam, inclusive, nos dias do exame, para levar os estudantes para o local das provas. 
autoconfiança dos alunos da escola publica de ensino médio do Ceará. Sinceramente, temo que o Enem/Sisu esteja sob ataque, de que ano que vem o Enem já não seja o mesmo e que o MEC desmonte a sistemática Enem/Sisu, esta que possibilitou que tantas pessoas entrassem na maratona, que tantos jovens pobres que em princípio não teriam chances, rompessem essa barreira e entrassem nos mais diversos cursos, nas mais diversas universidades e institutos públicos e particulares dos muitos estados brasileiros. 